\title{
The effect of smartphone usage on the upper extremity performance among Saudi Youth, KSA
}

\author{
Mohammed Khalid Alruzayhi, Muath Salman Almuhaini, Akrm Ibrahem Alwassel, Osama \\ Mansour Alateeq
}

College of Medicine, Al-Imam Mohammed Bin Saud Islamic University, Riyadh, Kingdom of Saudi Arabia

\begin{abstract}
The current study aims to investigate the effect of smartphone usage on the upper extremity performance among Saudi youth. A goniometer to measure the Range of Motion (ROM), the Smartphone Addiction Scale (SAS), McGill Pain scale and Chattanooga stabilizer were used to perform the current study on a sample of 300 university students from Al-Imam Mohammed Bin Saud University. The results have shown that smartphone addiction is negatively correlated to the elbow flexion, shoulder flexion, shoulder extension, shoulder abduction, shoulder adduction, and both shoulder internal and external rotation. Furthermore, the results have shown that McGill pain scores were positively correlated to elbow flexion, shoulder flexion, shoulder extension, shoulder abduction, shoulder adduction, and both shoulder internal and external rotation. The study has concluded that smartphone usage among Saudi youth negatively affects the upper extremity and causes a significant increase in the pain intensity. The study has recommended that there is an urgent need for a significant awareness campaign to warn the community regarding the impact of using smartphones for long periods of time.
\end{abstract}

KEYWORDS: smartphones, range of motion, upper extremity.

\section{INTRODUCTION}

Smartphones are considered to be the natural evolution of computers, which have contributed significantly to reduce the popularity of these devices after several decades of dominance. Smartphones have pushed the path towards the development of tablet PCs, which is a compromise between a smart phone and personal computers ${ }^{1}$.

Smartphones differ from traditional phones in that they provide a number of functions, advanced computing capabilities and advanced communication along with other traditional phone functions ${ }^{2}$.

Smartphones evolve day after day, their capacities and capabilities increasing spectacularly. Some of these phones have become equipped to use the fingerprint, for example, as a kind of safety to unlock the phone. On the other hand, some of them use the technique of following the eyes movement to surf the internet or view the images by just performing an aerobic pointing by the hand ${ }^{3}$. In general, almost all the functions of the smartphones require the individuals to stare sharply downwards or to hold their arms out in front of them to view the screen ${ }^{4}$.

Smartphone utilization is growing exponentially in the world, especially in Saudi Arabia ${ }^{5}$. According to a study performed by Nielsen Holding, it has been indicated that about $67 \%$ of the Kingdom population above sixteen years old use a smartphone. Investigating the youth category, the study reported that $73 \%$ of those using smartphones are under the age of 15 . In a study conducted by Alhassan et al. in 2016 it has been indicated that $52.7 \%$ of the males and $46.9 \%$ of the females ranging in age between 18 and 23 are addicted to using smartphones ${ }^{6}$. In a more recent study conducted by Alosaimi et al. it has been reported that $27.2 \%$ of the individuals ranging in age between 20 to 24 use their smartphones more than 8 hours ${ }^{7,8}$.

Several studies examined the impact of smartphones on the musculoskeletal system. For example, Alabdulwahab et al. performed a cross-sectional study entitled "smartphone use addiction can cause neck disability", that aimed to identify the level of smartphone addiction and its correlation to the neck function $^{4}$. The study sample was composed of 78 healthy young adults that were subjected to a Smartphone Addiction Scale (SAS) and Neck Disability Index (NDI). The findings have shown that there is a strong association between smartphone use and different degrees of neck problems among the participants ${ }^{4}$.

Earlier in 2011, Berolo et al. conducted a study that aimed to investigate the musculoskeletal symp- 
toms among mobile hand-held device users and their relationship to device users ${ }^{9}$. The study sample was composed of 140 university students, staff and faculty members. The results showed that $84 \%$ of the study participants reported pain in at least one body part. The right hand pain was the most common at the base of the right thumb. Moreover, there was a strong association between the total time spent using a mobile device and neck and right shoulder pain ${ }^{9}$.

In a retrospective study conducted by Sharan et al. ${ }^{10}$, that aimed to describe the risk factors and clinical features of the musculoskeletal disorders arising due to the usage of hand-held devices, the study sample was composed of 70 subjects characterized by having a musculoskeletal disorder affecting the upper extremities. The results showed that all the study participants reported pain in the thumb and forearm with associated burning, numbness and tingling around the thenar eminence of the hand. The study has reported that there is a correlation between mobile design and anthropometry of the user in causing discomfort and fatigue in hand, elbow and shoulder, while using hand-held devices ${ }^{10}$.

Although there are a number of studies investigating the impact of hand-held devices on the musculoskeletal system, there is still a clear shortage in data and responses regarding their impact. Studies have varied among the cross-sectional, retrospective and experimental designs, which indicate the absence of a fixed research approach to achieve the study aim of identifying the musculoskeletal disorders resulted from hand-held devices.

Furthermore, the majority of the studies did not include a rehabilitation protocol that could help the individuals to recover completely from the symptoms of the musculoskeletal disorders.

In the context of Saudi Arabia, there is a clear shortage of studies and data insufficiency regarding the musculoskeletal disorders caused by using the hand-held devices.

In the light of the studies shortage, the current study will be conducted to identify the impact of smartphone devices on the musculoskeletal disorders among a randomly selected sample of the community members varying in age range. Moreover, this study will contribute efficiently to enriching the available literature review concerning the musculoskeletal disorders due to the usage of smartphones, as it is a growing problem that has a large impact globally.

Finally, the on-going study proposes an effective sequenced rehabilitation program that helps in the recovery of the affected individuals.

The current study aims to investigate the effect of the smartphone usage on the upper extremity performance among Saudi youth.

\section{MATERIAL AND METHODS}

\section{Research design}

A cross-sectional study - observational study

Study setting

Al-Imam Mohammed Bin Abdul Aziz University.

\section{Study Subject}

The study sample will include 300 students enrolled in Al-Imam Mohammed Bin Saud University.

Inclusion criteria

- Age 18-25

- Voluntary participation

- Students enrolled in Al-Imam Mohammed Bin Saud University.

- Acceptable level in English (Speaking, reading and writing)

\section{Exclusion criteria}

- Non-student individuals

- Pregnant females

\section{Study instruments}

\section{Goniometer}

A goniometer is usually made of plastic and it is often transparent. Occasionally, goniometers are made of metal. There are two "arms" of the goniometer: the stationary arm and the moveable arm. Each arm is positioned at specific points on the body and the centre of the goniometer is aligned at the joint to be measured.

Steps to using a Goniometer:

1. Align the fulcrum of the device with the fulcrum or the joint to be measured.

2. Align the stationary arm of the device with the limb being measured.

3. Hold the arms of the goniometer in place while the joint is moved through its range of motion.

4. The degree between the endpoints represents the entire range of motion.

Assessment of elbow range of motion steps:

- Sitting study participant on a chair

- (Arm position): Arms are supported on the table

- Shoulder flexion (90 degrees)

- Then measure the range of motion

Assessment of shoulder range of motion ${ }^{11}$ :

- Trace arc while reaching forward with elbow straight (forward flexion).

- Should be able to move hand to position over head - normal range is 0 to 180 degrees.

- Reverse direction \& trace arc backwards (extension).

- Should be able to position hand behind their back.

- Direct patient to abduct their arm to position with hand above their head. 
- Movement should be smooth and painless.

- Normal range is 0 to 180 .

\section{The Smartphone Addiction Scale (SAS) ${ }^{12}$}

The assessment will include:

1. Duration of smartphone use on a typical day.

2. Frequency of smartphone use on a typical day.

3. Duration of time until first smartphone use in the morning upon waking.

4. The smartphone function with the most personal relevance.

Smartphone addiction will be assessed using the SAS: 10 - item self-report instrument. The SAS addresses the following 5 content areas:

- daily-life disturbance

- withdrawal

- cyberspace-oriented relationship

- overuse

- tolerance

3. McGill Pain Scale (Melzack, 1987) ${ }^{13}$

- A scale of rating pain developed at McGill University by Melzack and Torgerson

- A self-report questionnaire

- How to use:

- Users first select a single word from each group that best reflects their pain.

- Users then review the list and select the three words from groups 1-10 that best describe their pain.

- Two words from groups 11-15.

- A single word from group 16.

- and then one word from groups 17-20.

- Users can use some words more than once.

4. Chattanooga stabilizer pressure biofeedback Muscle isometric contraction

Muscle isometric contraction will be tested with Chattanooga stabilizer pressure biofeedback. The participant will be tested while moving the upper limb; the therapist will resist the movement using the stabilizer with his arm against the wall to prevent the substitution of the subject.

\section{Statistical analysis}

Data will be presented as mean and standard deviation, minimum and maximum values. Spearman and Pearson correlation coefficients will be used for assessing the relation between different variables.

\section{RESULTS}

Results shown in Table 1 represent the mean and standard deviation scores of the study variables. The same variable can be seen also in Figure 1.

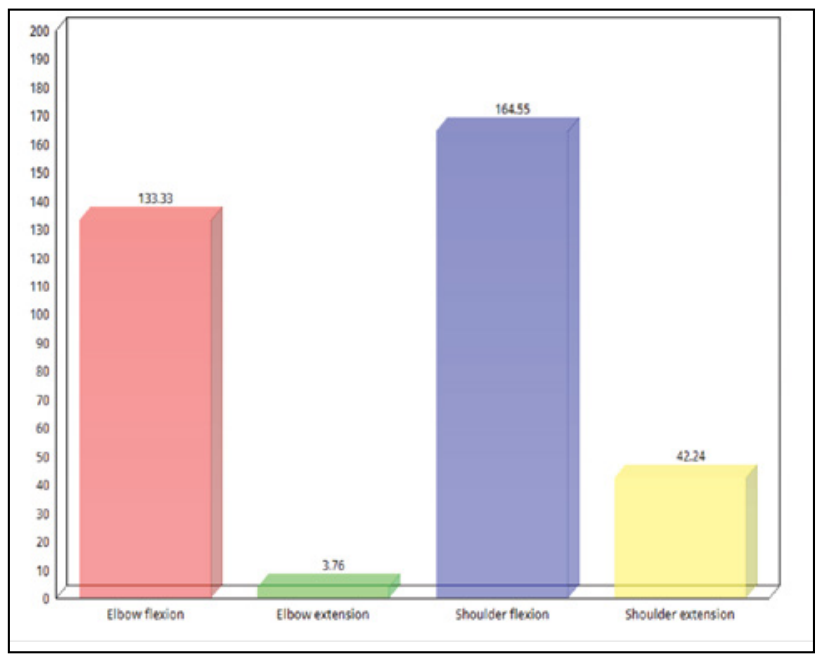

Figure 1 Mean values for the elbow flexion/extension and shoulder flexion/extension

\section{Table 1}

Mean and standard deviation scores of the variables evaluated in the study.

\begin{tabular}{ccc}
\hline Variable & Mean & Standard deviation \\
\hline Elbow flexion & 133.33 & 19.84 \\
\hline Elbow extension & 3.76 & 5.12 \\
\hline Shoulder flexion & 164.55 & 7.34 \\
\hline Shoulder extension & 42.24 & 7.35 \\
\hline
\end{tabular}

Results show that the mean score for the elbow flexion was $133.33 \pm 19.84$, for the elbow extension was $3.76 \pm 5.12$, for the shoulder flexion was $164.55 \pm 7.34$ and for the shoulder extension was $42.24 \pm 7.35$.

Table 2 shows the Spearman's rho correlation factor values between the participants' body mass index (BMI) and their elbow flexion, extension and shoulder flexion and extension.

The results show that:

- BMI is negatively correlated to elbow flexion $(-0.159)$, shoulder flexion (-0.342) and shoulder extension (-0.235).

- There is a weak positive correlation between participants' BMI and their elbow extension (0.11).

Table 2

Spearman's rho correlation results

\begin{tabular}{cccccc}
\hline & BMI & Elbow flexion & Elbow extension & Shoulder flexion & Shoulder extension \\
\hline BMI & 1.00 & -0.159 & 0.11 & -0.342 & -0.235 \\
\hline
\end{tabular}


The correlation between elbow flexion/extension and shoulder flexion/extension to the smartphone addiction scale and McGill pain scale indicate that smartphone addiction is negatively correlated to the elbow flexion, elbow extension, shoulder flexion and shoulder extension (Table 3). On the other hand, results indicate that McGill pain responses have been positively correlated to the elbow flexion/extension and shoulder flexion/ extension.

\section{Table 3}

Spearman's' rho correlation coefficient values among smartphone addiction, pain intensity, and elbow, shoulder and wrist range of motion (ROM).

\begin{tabular}{ccc}
\hline Measurement & Smartphone Addiction & McGill pain score \\
\hline $\begin{array}{c}\text { Elbow flexion/ } \\
\text { extension }\end{array}$ & -0.146 & 0.206 \\
\hline $\begin{array}{c}\text { Shoulder extension/ } \\
\text { flexion }\end{array}$ & -0.107 & 0.137 \\
\hline
\end{tabular}

Measurements of the shoulder abduction, adduction, internal and external rotation have yielded a mean score equal to $165.6,11.3,83.4$ and 84.2 , respectively (Table 4).

\section{Table 4}

Mean and standard deviation values for the shoulder abduction, adduction, internal and external rotation.

\begin{tabular}{ccc}
\hline & Mean & Standard deviation \\
\hline Shoulder abduction & 165.6 & 19.9 \\
\hline Shoulder adduction & 11.3 & 7.00 \\
\hline Internal rotation & 83.4 & 4.8 \\
\hline External rotation & 84.2 & 13.1 \\
\hline
\end{tabular}

The investigation of BMI correlation to the shoulder abduction, adduction, internal and external rotation has shown that BMI was negatively correlated to the shoulder abduction and external rotation, while it was positively correlated to the shoulder adduction and the internal rotation (Table 5).

Table 5

Correlation coefficient values among BMI and the wrist flexion/ extension, and ulnar/radial deviation.

\begin{tabular}{cc}
\hline & BMI \\
\hline Shoulder abduction & -0.087 \\
\hline Shoulder adduction & 0.074 \\
\hline Internal rotation & 0.374 \\
\hline External rotation & -0.052 \\
\hline
\end{tabular}

Results shown in Table 5 indicate that smartphone addiction is negatively correlated to shoulder abduction/adduction and shoulder internal/external rotation.

On the other hand, the McGill pain score was positively correlated with shoulder abduction/adduction and shoulder internal/external rotation measurements (Table 6).

Table 6

Correlation coefficient values among smartphone addiction, pain intensity, and elbow, shoulder and wrist ROM.

\begin{tabular}{ccc}
\hline Measurement & Smartphone Addiction & McGill pain score \\
\hline $\begin{array}{c}\text { Shoulder abduction/ } \\
\text { adduction }\end{array}$ & -0.213 & 0.183 \\
\hline $\begin{array}{c}\text { Shoulder internal/ex- } \\
\text { ternal rotation }\end{array}$ & -0.171 & 0.246 \\
\hline
\end{tabular}

Findings shown in Table 7 indicate that $65 \%$ of the study samples were within the addicted category, while $35 \%$ of the female students were within the non-addicted smartphone users. Mean and standard deviation scores have shown that the total SAS score for addicted users was $38.31 \pm 3.16$, on the other hand, the total SAS score for the non-addicted user was $22.71 \pm 1.29$

Table 7

Total score of SAS responses.

\begin{tabular}{cccccc}
\hline & N & $\%$ & Mean & SD & $\begin{array}{c}\text { Total SAS } \\
\text { score }\end{array}$ \\
\hline Addicted users & 13 & $65 \%$ & 1.22 & 0.73 & $38.31 \pm 3.16$ \\
\hline $\begin{array}{c}\text { Non-addicted } \\
\text { users }\end{array}$ & 7 & $35 \%$ & 1.01 & 0.39 & $22.71 \pm 1.29$ \\
\hline
\end{tabular}

Results shown in Table 8 indicate that there is a significant positive correlation between smartphones and shoulder abduction among the study participants.

Measurements of the wrist flexion, extension, ulnar deviation and radial deviation have yielded a mean score equal to 72.85, 68.93, 42.56 and 31.60 , respectively (Table 9 ).

The investigation of BMI correlation with the wrist flexion/ extension and ulnar/radial deviation has shown that BMI is negatively correlated with the wrist flexion, extension, ulnar deviation and wrist radial deviation, as shown in Table 10. 
Table 8

Correlation coefficient values among SAS scores and ROM of shoulder and elbow.

\begin{tabular}{cccccccc}
\hline & $\begin{array}{c}\text { Shoulder } \\
\text { flexion }\end{array}$ & $\begin{array}{c}\text { Shoulder } \\
\text { extension }\end{array}$ & $\begin{array}{c}\text { Shoulder } \\
\text { abduction }\end{array}$ & $\begin{array}{c}\text { Shoulder } \\
\text { adduction }\end{array}$ & $\begin{array}{c}\text { Shoulder } \\
\text { external rotation }\end{array}$ & $\begin{array}{c}\text { Shoulder } \\
\text { internal rotation }\end{array}$ & $\begin{array}{c}\text { Elbow } \\
\text { flex }\end{array}$ \\
\hline SAS & 0.22448 & 0.11094 & $0.45852^{*}$ & 0.10415 & 0.2719 & 0.01992 & 0.09088 \\
\hline Elbow & Wrist flexion & $\begin{array}{c}\text { Wrist } \\
\text { extension }\end{array}$ & $\begin{array}{c}\text { Wrist radial } \\
\text { deviation }\end{array}$ & $\begin{array}{c}\text { Wrist ulnar } \\
\text { deviation }\end{array}$ & BMI & MA \\
\hline SAS & 0.24931 & 0.3622 & 0.17414 & 0.12911 & 0.18811 & 0.16629 & 0.24669 \\
\hline
\end{tabular}

Table 9

Mean and standard deviation values for the wrist flexion/ extension, and ulnar/radial deviation.

\begin{tabular}{ccc}
\hline & Mean & Standard deviation \\
\hline Wrist flexion & 72.85 & 28.95558 \\
\hline Wrist extension & 68.93 & 16.77814 \\
\hline Ulnar deviation & 42.56 & 7.5893249 \\
\hline Radial deviation & 31.60 & 8.503987 \\
\hline
\end{tabular}

Table 10

Correlation coefficient values among BMI and the wrist flexion/ extension and ulnar/radial deviation.

\begin{tabular}{cc}
\hline & BMI \\
\hline Wrist flexion & -0.077 \\
\hline Wrist extension & -0.562 \\
\hline Ulnar deviation & -0.261 \\
\hline Radial deviation & -0.264 \\
\hline
\end{tabular}

Results shown in Table 10 indicate that smartphone addiction is negatively correlated with wrist flexion and extension, and both ulnar and radial deviation.

On the other hand, the McGill pain score was positively correlated with the previously mentioned measurements (Table 11).

\section{Table 11}

Mean and standard deviation values for the wrist flexion/ extension, and ulnar/radial deviation.

\begin{tabular}{ccc}
\hline Measurement & $\begin{array}{c}\text { Smartphone } \\
\text { Addiction }\end{array}$ & McGill pain score \\
\hline $\begin{array}{c}\text { Wrist flexion/ } \\
\text { extension }\end{array}$ & -0.231 & 0.381 \\
\hline $\begin{array}{c}\text { Ulnar/ } \\
\text { Radial deviation }\end{array}$ & -0.136 & 0.163 \\
\hline
\end{tabular}

Results presented in Table 12 show that study participants were divided into four subgroups according to the McGill pain questionnaire responses. The mod- erate pain group constituted $45 \%$ of the total study sample, followed by the mild pain group that represented $35 \%$, the severe pain subgroup $(15 \%)$, and finally the no pain subgroup that constituted $5 \%$ of the total study sample.

Table 12

Mean and standard deviation values for the McGill pain questionnaire responses.

\begin{tabular}{ccccc}
\hline Pain subgroup & N & $\%$ & Mean & SD \\
\hline No Pain & 1 & $5 \%$ & 0.81 & 0.39 \\
\hline Mild Pain & 7 & $35 \%$ & 1.16 & 0.76 \\
\hline Moderate Pain & 9 & $45 \%$ & 2.07 & 0.63 \\
\hline Severe Pain & 3 & $15 \%$ & 2.89 & 0.71 \\
\hline
\end{tabular}

Table 13 shows the correlation results among the McGill pain scores and elbow, shoulder and wrist ROM. McGill pain score was positively correlated with the elbow flexion/extension, shoulder extension/ flexion, shoulder abduction/adduction, shoulder internal/external rotation and wrist flexion/extension (Table 13) .

Table 13

Correlation coefficient values among BMI and the wrist flexion/ extension and ulnar/radial deviation.

\begin{tabular}{cc}
\hline Measurement & McGill pain score \\
\hline Elbow flexion/extension & 0.206 \\
\hline Shoulder extension/flexion & 0.137 \\
\hline Shoulder abduction/adduction & 0.183 \\
\hline Shoulder internal/external rotation & 0.246 \\
\hline Wrist flexion/external & 0.381 \\
\hline Ulnar/Radial deviation & 0.163
\end{tabular}

\section{DISCUSSIONS}

Results are consistent with Golden et al. ${ }^{14}$ results which indicated that BMI was negatively correlated with the elbow range of motion, elbow flexion. Also, 
they are in accordance with Wong et al. study results which reported that BMI is significantly correlated with the wrist flexion and extension ${ }^{15}$.

Moreover, the current study results are consistent with the results of Gill et al. ${ }^{16}$ study results who found that shoulder flexion, abduction and internal rotation were not significantly affected by body mass index (BMI).

Correlation results regarding the elbow, shoulder and wrist, the smartphone addiction and pain intensity are compatible with El-Azab et al. ${ }^{17}$ results that reported that the severity of the symptoms in the upper extremity is significantly associated with time for daily using of smartphones, and revealed that an increased duration of use of smartphones increase its negative effects due to faulty posture, pain and muscle fatigue. The study aimed to investigate the effect of smartphone usage on the upper extremity performance among Al Jouf University female students, by studying a random sample composed of 20 female students. The results showed that $65 \%$ of the studied female students were addicted smartphone user.

Moreover, our results are consistent with Berolo et al. and Um who found that pain and muscle fatigue increased with longer duration of smartphone usage $^{9,18}$.

By comparing our results to the previously performed studies results, the current study results were inconsistent with Alhassan et al. findings, which reported that $26.7 \%$ of the medical students are addicted to smartphone usage ${ }^{6}$.

Moreover, results are not in accordance with Alosaimi et al. who reported that $27.2 \%$ of the university students spend more than 8 hours per day using their smartphones ${ }^{7}$.

The findings have indicated that wrist flexion and extension are negatively correlated with the smartphone addiction scale scores, and positively correlated with McGill pain scores. In 2015, Inal et al. reported that wrist flexion or extension is linked to increased carpal tunnel pressure, and it also decreases the amount of space available for the median nerve in the carpal tunnel ${ }^{19}$. So, they hypothesized that repetitive wrist flexion and extension during smartphone use may also impact the median nerve, as indicated by larger median nerves in high smartphone users. According to them, the extensive flexion/extension of the thumb and wrist occurs when an individual uses a smartphone. Placing thumbs and wrists in static postures will likely lead to an increased load on these joints, associated with a decreased strength of muscles and tendons. These findings could explain the positive correlation between smartphone usage and the McGill pain scores ${ }^{19}$.

The current study findings are consistent with Inal et al. ${ }^{19}$ who found that Visual Analogue Scale (VAS) pain in movement was also found to be significantly higher in the high smartphone-user group than in the lower smartphone-user group.

In 2006, Woo et al. found that ulnar and radial deviations are negatively affected by the prolonged usage of smartphones ${ }^{20}$. They have reported that the gradual reduction in the cross sectional area of the median nerve, with thumb opposition together with the wrist in ulnar deviation, cause the greatest extent of deformation of the median nerve.

Our study results have been consistent with Cote et al. findings which indicated that pain intensity measured using the McGill pain scale was positively correlated with the shoulder and wrist range of motion ${ }^{21}$.

At the same time, our findings are in accordance with Inal et al. study results that have reported a significant correlation between pain intensity and upper extremity ROM among smartphone users ${ }^{19}$.

Conflict of interest: The authors have no conflict of interest.

Contribution of authors: All authors have equally contributed to this work.

Ethical Approval: The study was performed under the institutional research and ethics committee.

Acknowledgements: Authors acknowledge the unlimited support and encouragement of the colleagues in the medicine department and the administration of Al-Imam Mohammad Bin Saud Islamic University for facilitating the current study.

\section{REFERENCES}

1. Sarwar M., Soomro TR. Impact of smartphone's on society. European Journal of Scientific Research. 2013;98(2):216-26.

2. Mokoena S. Smartphones and regular cellular phones: assessing their impact on students' education at the University of Zululand (Doctoral dissertation, University of Zululand). 2012. Available from: http://uzspace.uzulu.ac.za/handle/10530/1049.

3. Shahzad M, Liu AX, Samuel A. Secure unlocking of mobile touch screen devices by simple gestures: you can see it but you cannot do it. In: MobiCom'13 Proceedings of the 19th annual international conference on Mobile computing \& networking. ACM. New York; 2013, p.39-50.

4. AlAbdulwahab SS, Kachanathu SJ, AlMotairi MS. Smartphone use addiction can cause neck disability. Musculoskeletal Care. 2017;15(1):10-2. DOI: 10.1002/msc.1170. Epub 2017 Jan 19.

5. Poushter J. Smartphone ownership and internet usage continues to climb in emerging economies [Internet]. Pew Research Center. 2016. Available from: http://www.pewglobal.org/2016/02/22/smartphone-ownershipand-internet-usage-continues-to-climb-in-emerging-economies/

6. Alhassan M, Al Mulhim A, Sultan S, Alnofaily H, Alfayez M, Alfarhan H, et al. Smartphone usage among medical students in Saudi Arabia. International Journal of Science and Research (IJSR). 2017;6(1):2227-9. Available from: https://www.ijsr.net/archive/v6il/v6i1_02.php

7. Alosaimi FD, Alyahya H, Alshahwan H, Al Mahyijari N, Shaik SA. Smartphone addiction among university students in Riyadh, Saudi Arabia. Saudi Med J. 2016;37(6):675-83. DOI: 10.15537/Smj.2016.6.14430. 
8. Smartphones Dominate The KSA Mobile Market [Internet]. 2014. Available from: http://www.nielsen.com/mena/en/press-room/2014/ smartphones-dominate-the-ksa-mobile-market.html [Accessed 19 Mar. 2017].

9. Berolo S, Wells RP, Amick BC. Musculoskeletal symptoms among mobile hand-held device users and their relationship to device use: A preliminary study in a Canadian university population. Appl Ergon. 2011;42(2):371-8. DOI: 10.1016/j.apergo.2010.08.010. Epub 2010 Sep 15.

10. Sharan D, Mohandoss M, Ranganathan R, Jose J. Musculoskeletal disorders of the upper extremities due to extensive usage of hand held devices. Ann Occup Environ Med. 2014;26:22. DOI: 10.1186/s40557-014-0022-3.

11. Armstrong AD, MacDermid JC, Chinchalkar S, Stevens RS, King GJ Reliability of range-of-motion measurement in the elbow and forearm. J Shoulder Elbow Surg. 1998;7(6):573-80.

12. Kwon M, Kim DJ, Cho H, Yang S. The smartphone addiction scale: development and validation of a short version for adolescents. PLoS ONE. 2013;8(12):e83558. https://doi.org/10.1371/journal.pone.0083558.

13. Melzack R. The short-form McGill Pain Questionnaire. Pain. 1987;30(2):191-7.

14. Golden DW, Wojcicki JM, Jhee JT, Gilpin SL, Sawyer JR, Heyman MB. Body mass index and elbow range of motion in a healthy pediatric population: a possible mechanism of overweight in children. J Pediatr Gastroenterol Nutr. 2008;46(2):196-201. DOI: 10.1097/ MPG.0b013e31812f568b.
15. Wong DSW, Chan HC, Cheng CHK. Cyberbullying perpetration and victimization among adolescents in Hong Kong. Child Youth Serv Rev. 2014;36:133-140. DOI: 10.1016/j.childyouth.2013.11.006.

16. Gill H, Gustafsson L, Hawcroft L, McKenna K. Shoulder joint range of motion in healthy adults aged 20 to 49 years. British Journal of Occupational Therapy. 2006;69(12):556-61. https://doi. org/10.1177/030802260606901204.

17. El Azab DR, Amin DI, Mohamed GI. Effect of smart phone using duration and gender on dynamic balance. Int J Med Res Health Sci. 2017;6(1):42-9.

18. Um SH. An empirical study on relationship between physical symptoms and smart phone usage. Incheon Inha University. Dissertation of Master's Degree. 2013.

19. Inal EE, Demirci K, Cetintürk A, Akgönül M, Savaș S. Effects of smartphone overuse on hand function, pinch strength, and the median nerve. Muscle Nerve. 2015;52(2):183-8. DOI: 10.1002/mus.24695. Epub 2015 Jun 3 .

20. Woo HC, White P, Ng HK, Lai CW. Development of kinematic graphs of median nerve during active finger motion: implications of smartphone use. PLoS One. 2016;11(7):e0158455. https://doi.org/10.1371/journal. pone. 0158455 .

21. Côté JN, Raymond D, Mathieu PA, Feldman AG, Levin MF. Differences in multi-joint kinematic patterns of repetitive hammering in healthy, fatigued and shoulder-injured individuals. Clin Biomech (Bristol, Avon). 2005;20(6):581-90. Epub 2005 Apr 14. 